fully made autopsy failed to throw any light upon the cause of her malady. A most rigorous examination of the sympathetic was made, both with the naked eye and with the aid of the microsenpe, but it appeared to be in all respects perfectly heulthy.* Trousseau sums up his opinion by saying be considers that exophthalmic goitre is the result of " a neurosis of the sympathetic." $\dagger$

The weight of opinion, then, seems to lie in favour of the cause lying in some pathological condition of the sympathetic; but what the nature of-that is, the precise nature of - that pathological state may be, we have not, as yet, sufficient light to enable us to discern; it has, however, been made clear to demonstration that there need not be, of necessity, any absolute alteration of organic nerve structure for the development of the disorder, but, just as we are all aware that, through the aid of the sympathetic, and as the result of its normal function, local natural congestions may and do take place, so, pathologically, this system of nerves may effect congestions of an extraordinary and unnatural kind. From these considerations, I think some justification may be found for the belief that experimental research in the direction of the sympathetic, and the pathological influence exercised by it at times on the vaso-motor apparatus, would afford an ample reward to the industrious investigator by the discovery of the, at present, unknown cause of exophthalmic goitre.

During the time that B- S- (Case 1) was in the infirmary it so happened that I had the opportunity of showing the patient to Dr. B. W. Richardson, and he propounded a novel view as to the cause of exophthalmic goitre; but, as he informed me that he proposed putting this view before the profession ere very long, I cannot fairly do more than make this passing allusion to it.

Hitherto, then, the treatment of the disease has been very largely of an empirical character, and, as far as drugs are concerned, I think the general opinion of those who have had the management of such cases may be summed up as follows: Iron may be given, digitalis should be given, iodine must not be given.

With my own cases I have found that great quiet, freedom from excitement, a mild, plain, non-stimulating diet, attention to the digestive functions, and a residence in a pure and healthy atmosphere, have proved efficient auxiliaries (I dare not call them more) in promoting recovery; whilst I fancy-it may only be a fancy-that I have seen iron, but much more frequently digitalis, do some real service in modifying the heart symptoms, and, to this extent, contributing towards the cure.

\section{THE LOCAL TREATMENT OF PSORIASIS.}

By WYNDHAM COTTLE, M.A. Oxon., F.R.C.S. ENG., BHNIOR ASSISTANT gUREEON TO THE FOSPITAT FOB DISBASBS OF THB SKIN, BLA CKFRIARS.

THERE are a class of cases of psoriasis, namely those not uncommon examples where there is an excessive formation of dry scales, in many instances even producing the thick crusts with which observers of this complaint are familiar, and forming in chronic and neglected cases as long as they remain an insuperable obstacle to recovery. This condition is very common in congenital and inveterate cases, and when in the neighbourhood of the joints these crusts form hard shells, they preclude movement, or at least restrict it, and render it painful. It is to such cases as these that $I$ have found the treatment I am about to suggest applicable. The consideration that a material improvement in the condition of parts might be expected to follow the hindrance of evaporation locally, led me to endeavour to procure such a result. After various trials $I$ have found the subjoined method most advantageous.

All crusts and scales having been removed as far as possible, and the absence of grease being ensured by wiping the parts with ether or rectified spirit, and the skin thoroughly dried, the solution of india-rubber is thickly

* Union Médicale, 1868.

† Trousseau's Clin. Medicin $\theta$ (Syd. Soc. Trans.), vol, i,s p. 678, applied with a brush over the affected places, and this application renewed as often as is needful for the formation and maintenance of a continuous covering of india-rubber over the affected skin. The chief difficulty I encountered lay in procuring complete adhesion of this covering, and in this respect I found india-rubber much superior to guttapercha or collodion flexile, \&c. A very good solution has been supplied to the hospital by Messrs. Allen and Hanbury, of Plough-court, and which answers very fairly when carefully applied. Its composition is, india-rubber half an ounce, chloroform eleven ounces and a half. Solutions in ether were not found so suitable as those in chloroform, for, from their more speedy solidification by evaporation, some diff. culty was experienced in their use, especially in the hands of patients.

I would claim for this mode of treatment that, in the majority of the class of cases mentioned, the recovery has been more rapid than with the ordinary local measures, and also very comfortable to the patient, free from the objectionable odour of the tar compounds; that its action is confined to the affected parts themselves, requiring no confinement of the patient, nor indeed causing any inconvenience to him ; a further recommendation being its ease of application. At the same time I would guard against its being understood that I find this a local method of treatment to be indiscriminately used in this often somewhat intractable complaint, for the pathological conditions that call for the employment of some such remedy do not present themselves in the majority of cases; still I think it may be found a useful adjunct to the recognised treatment, and in a large percentage of appropriate instances give very g ood results. The mode of action of these coverings, that are impervious to moisture, seems to be that they prevent evaporation, and hinder the loss of the natural perspiration of the part. The result with which perhaps we are more concerned is that the affected skin, previously dry and harsh, and with its natural elasticity diminished, becomes supple, and almost moist, while the scales and crusts show little or no tendency to reform, any that may have been reproduced coming off with the india-rubber, leaving the skin almost normal beneath. After a time the deep red colour of the patches fades, there remaining eventually liktle more than the staining of the skin that always persists for some time.

This mode of treatment of course is not suited to cases in an acute stage, or in which excessive action is present. I have employed it in upwards of fifty cases, chiefly at the hospital, the details of which would occupy too great a space. I will, however, quote one typical instance.

A young woman, nineteen years of age, was admitted to the hospital on March 8th. She was of strumous appearance, but otherwise in fair health. Her affection had existed from childhood with varying degrees of intensity, sometimes leaving her almost free, but with ever-recurring exacerbations. On admission her condition was as follows. Irregular patches, averaging about an inch and a half in diameter, were scattered over the body, and more thickly on the outer aspect of the limbs, and especially about the elbows and knees, extending over the wrists and hands. These patches had a base of inflamed and thickened cutis, overlying and firmly adherent to which were hard and dry crusts, the results of hyperplastic action of the cuticular elements of the usual psoriasis type, in places exceeding the eighth of an inch in thickness, most abundantly developed around the elbows and knees. These crusts having been removed, to one side of the body and corresponding limbs the indiarubber solution was applied, while, to gain a comparative result, the other side was treated with mercurial and tar compounds. The affected places on the side to which the india-rubber solution was used at the end of three weeks became mere red markings, having lost in great measure their thickened bases, with but little tendency to the formation of scales remaining, while on the opposite side they continued to be produced, though with lessened activity, the inflammatory condition persisting. The india-rubber solution was then applied to the whole of the patches. She was discharged on May 3rd with only red stains to mark the former sites of the disease. The usual constitutional treatment was pursued.

In many of my other cases also one side or limb has in like manner been treated with these impermeable coverings, the corresponding parts receiving the more ordinary applications to allow of comparison of their actions. 
The same local treatment ia applicable also to some con. ditions of chronic eczema, but I have not as yet brought my experiments in that direction to a conclusion.

Savile-row, $\mathrm{W}$.

\section{A}

\section{HOS PITAT PRACTICE, BRITISH AND FOREIGN.}

Nulla antem est alia pro certo noseendi via, nisi quamplurimas et morborum ot dissectionum historias, tum aliorum, tum proprias collectas habere, et inter se comparare.-Mongagn I De Sed. et Caub. Morb., lib.iv. Procmium.

\section{ST. THOMAS'S HOSPITAL.}

POPLITEAL ANEURISM ; APPLICATION OF ESMARCH'S BANDAGE FOR ONE HOUR, AND OF THE TOURNIQUET TEMPORARILY AFTERWARDS ; RECOVERY.-REMARKS.

(Under the care of Mr. WAGSTAFFE.)

THE following notes were taken by Mr. Edmunds, housesurgeon, and $\mathrm{Mr}$. Cockell, dresser.

R. W-, a barman, of good physique, aged thirty-two, was admitted September 1st. Between four and five months previously, when pushing a heary cask, he felt "something snap" in his right leg at the back of the knee, and he suffered for the next three days from severe pain in this situation, but did not discontinue his work. He felt pain there afterwards on and off after a hard day's work. Two months prior to admission he first noticed "throbbing" at the back of the right knee, attended for the last month with swelling of the leg and "dragging pain" at the back of the leg and ankle; but he was able to continue his work until admitted.

On admission, there existed in the popliteal space a pulsating aneurismal tumour, two inches long, filling the upper half of the space, terminating opposite the junction of the femur with the tibia, together with considerable wdema of the leg.

On Sept. 2ud an Esmarch's bandage was applied tightly over the foot and leg up to the lower border of the popliteal space, carried lightly over the tumour (a thin layer of cotton-wool intervening), and then continued tightly over the thigh to within three inches and a half of Poupart's ligament, where the upper end of the bandage was fixed with pins. The elastic ligature was not used. This was completed at $2 \mathrm{P}$ Mr. The bandage was then left on for one hour, during wbich time the patient was very restless and complained of great pain. One-third of a grain of morphia was given subcutaneously. At 2.55 P.M. a tourniquet was placed on the femoral artery, and Esmarch's bandage was removed. A second tourniquet was placed in position, to be applied alternately with the first.-4 P.M. : No pulsation in tumour when the tourniquet was removed for a few moments. - 5.45 P Jr. : Application of the tourniquet continued; no pulsation in tumour; leg slightly swollen; toes warm.-9.30 P.M.: Until this time complete pressure had been kept up by tourniquets, but some flow of blood was now permitted.

3rd. $-845 \mathrm{~A}$ ㅍ. : When all pressure was taken off, no pulsation was felt in the tumour. Tourniquet still applied lightly.-At 12 noon there was no pulsation in the tumour, but the artery on the inner condyle pulsated. -7 P.M. : Tourniquet loose; taken off. Aneurism cured.

On the 10th the aneurism remained only as a solid lump in the popliteal space, and over each condyle was a rather large artery pulsating very freely. The foot was not swollen, and the man was froe from pain.

Remarks by Mr. WAGSTAFFE.-The value of the principle which Prof. Esmarch has been most active in utilising in his method of ensuring bloodless surgery has been recognised in England perhaps more fully than abroad; and one of the latest adaptations of it is in the treatment of aneurism. The only case in which I am aware of an attempt having been made to cure this disease by means of Esmarch's bandage is tbat of Dr. Walter Reid, reported in THe LANCET of September 25th, 1875 ; and in this case, which was one of popliteal aneurism, other means had been previously adopted : genuflexion for four days; complete compression of the artery for four hours, after which pulsation in the tumour ceased for a time; and then a number of attempts were made both by digital and instrumental compression before using Esmarch's bandage. So that, although there is no doubt that ultimately the complete emptying of the limb of blood by means of Esmarch's bandage allowed the aneurism to consolidate, still one cannot help feeling that the previous treatment may have materially assisted in the cure.

In the case here narrated the limb was emptied of blood for nearly an hour, the sac of the aneurism being left probably full, and then the main artery compressed by tourniquet for an hour longer, before the tumour was examined. At the end of that time no pulsation could be detected when the tourniquet was raised. Still it was thought advisable to continue the pressure, and this was probably nearly complete for the next five hours, after which it was maintained only imperfectly for twelve, and very slightly, if at all, for the next ten hours. The plan here adopted of leaving Esmarch's bandage compressing the whole limb, except the aneurism itself, for an hour, appears simpler and open to less objection than that adopted by Dr. Reid, of removing the bandage after encircling the upper part of the limb with the elastic ligature, inasmuch as it substitutes a universal for a local pressure; and doubtless, if it were thought advisable, the bandage might be left on longer, though it would be necessary to administer chloroform in that case, owing to the pain it produces. Many cases of necrosis remain under chloroform, with no blood admitted to the limb, a longer time than was occupied in the treatment of these two cases of aneurism-i.e., longer than an hour.

The treatment here adopted is undoubtedly more reliable than digital or instrumental pressure, but whether so successful in large thinly-coated aneurisms remains to be proved. The sac is presumably occupied by the clotting of the contained blood en masse, and not by a lamination from the wall inwards, and it remains to be seen whether this would ensure permanent obliteration in large aneurisms.

\section{EAST LONDON CHILDREN'S HOSPITAL.}

\section{A CASE OF ENCEPHALOID KIDNEY.}

(Under the care of Dr. MAgrath.)

For the notes of the following case we are indebted to Dr. Ralph W. Leftwich :-

Albert S—, aged ten months, was admitted March 30th, 1876. He was said to have been perfectly healthy until the age of seven months, when a lump about the size of a large egg was felt in the left side of the abdomen. From that time the child was fretful, and for two months previous to admission had been getting thinner. The lump steadily increased in size in all directions, and was said to vary in consistence. It had never been tender. Six weeks before admission the child had measles, but recovered perfectly from the attack. He was weaned a fortnight before admis. sion, and then had bilious vomiting for two days. The bowels had always been regular; there were no urinary symptoms. Father and mother fairly healthy; no miscarriage or stillbirth; five other children living, all healthy; one child died, aged sixteen months, of convulsions. No relation known to have had cancer. The mother, when advanced three months in her pregnancy with this boy, laid out a woman who died of abdominal tumour.

On admission the child appeared well nourished, had a clear complexion and red lips. A few enlarged glands were present in the neck. Chest healthy; abdomen prominent on the left side; no enlargement of sup rficial veins. A tense, elastic, non-fluctuating tumour, of irregularly rounded form, could be felt occupying chiefly the left half of the abdomen. It extended upwards beneath the false ribs, and backwards as far as the transverse processes. Traced forwards, it was superficial as far as the umbilicus, where it gradually receded from the surface, and was lost about four inches to the right of this point; the receling portion, except for about half an inch, was covered by the bowels. 